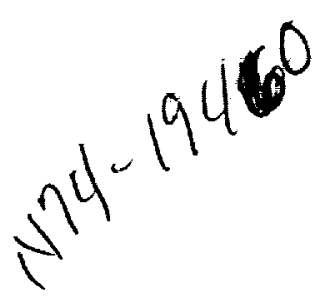

\title{
24. Possible Evidence of Ablation on Cosmic Dust Particles
}

\author{
Curtis L. Hemenway \\ Dudley Observatory and \\ State University of New York at Albany \\ Albany, New York
}

$\ddot{O}^{\prime \prime}$ PIK (1937) AND WHIPPLE (1950) have pre= dicted that small dust particles should be able to enter the Farth's atmosphere without reaching their melting temperature and thus retain their original shape prior to entry. They have shown that the critical size is a strong function of velocity as well as the physical parameters of the dust particle, A number of investigators have collected particles at high altitude believed to be of this type (Hemenway and Soberman, 1962; Wright and Hodge, 1964; Thomsen, 1963). This brief paper presents possible evidence of the existence of small bodies collected with our Sesame collector (Hemenway et al., 1967; Hemenway et al., 1971) which apparently werc sufficiently large to experience surface ablation and melting.

Figure 1 shows a scanning electron micrograph of a $19 \mu$ diameter, irregular particle col-

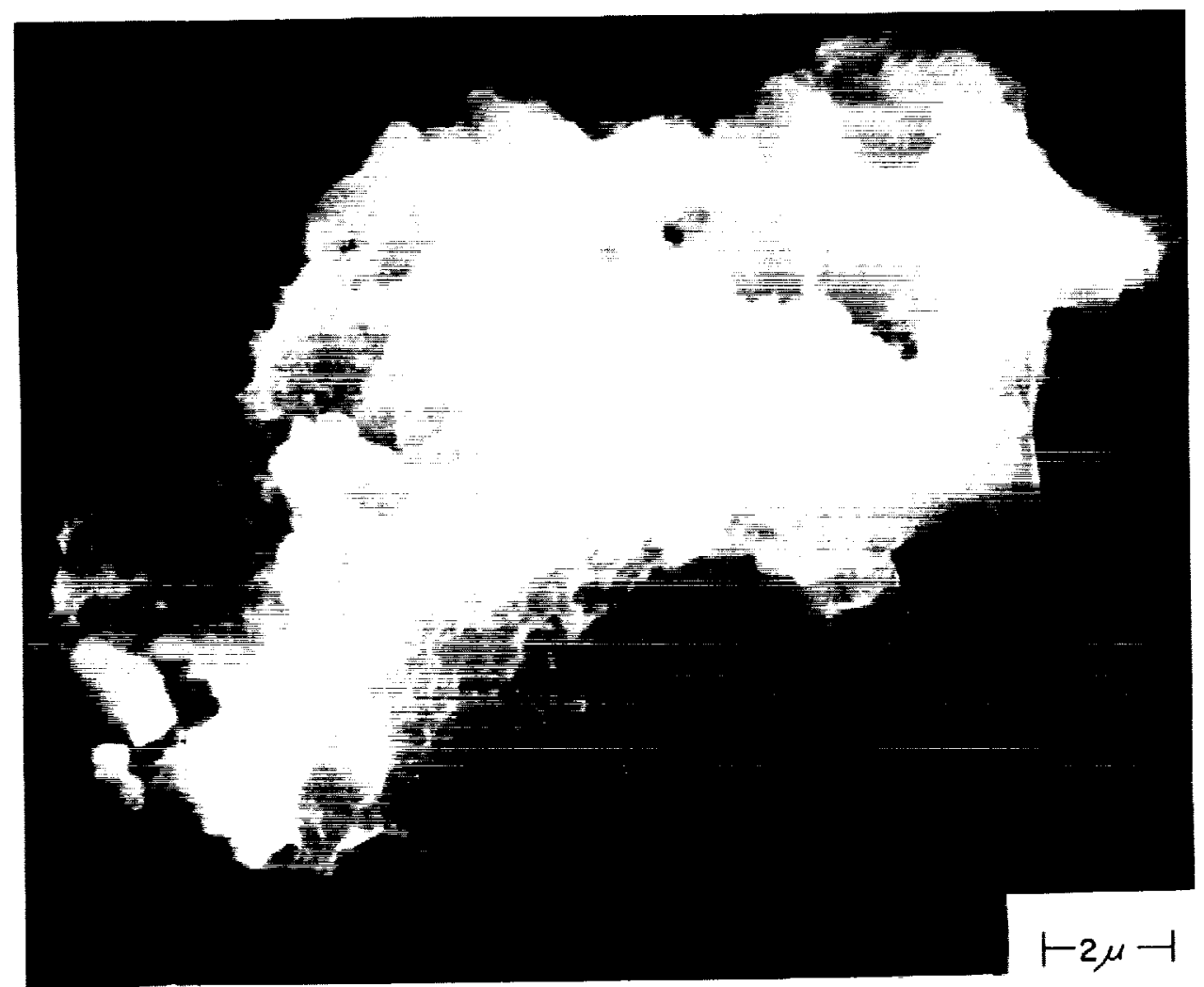

Figurf 1.-Ablated partıcle with reentrant cavities. 


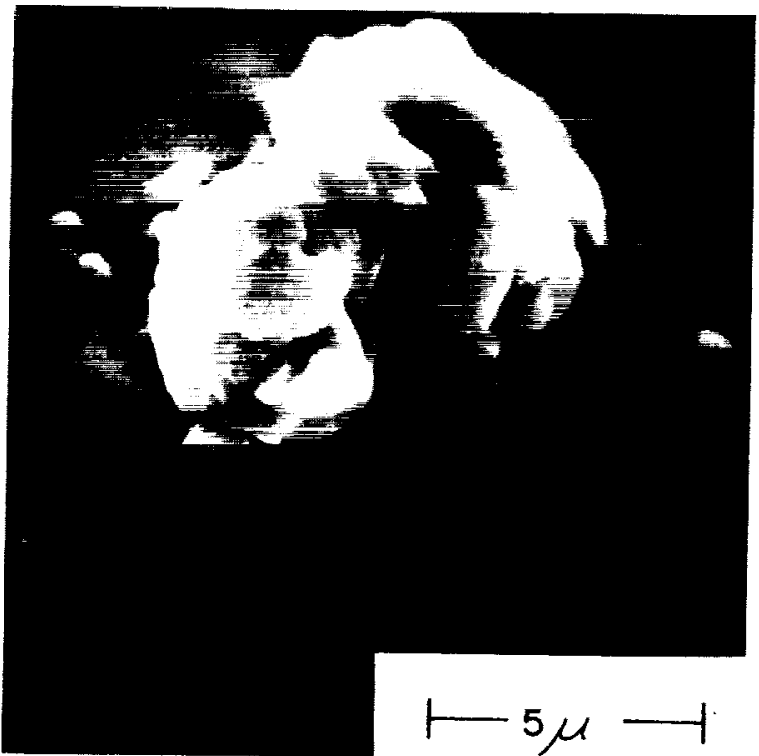

FIGURE 2.-Ablated particle with rounded nodules. lected August 13, 1970. This particle has reentrant cavities over much of its surface and appears to have surface characteristics somewhat similar to those of much larger meteoritic bodies. This particle has a number of small melted nodules over much of its surface.

Figure 2 shows a scanning micrograph of a $14 \mu$ diameter irregular particle collected November 18, 1967, having numerous rounded nodules. This particle (fig. 2) is similar to that published in Space Research XI (Hemenway et al., 1971). Both of these particles were collected shortly after the Leonid meteor shower.

Figure 3 shows a $63 \mu$ diameter irregular particle collected August 14, 1966, and may have been stably oriented during entry such that only one side experienced significant ablation. Parallel flow marks can be seen on this particle.

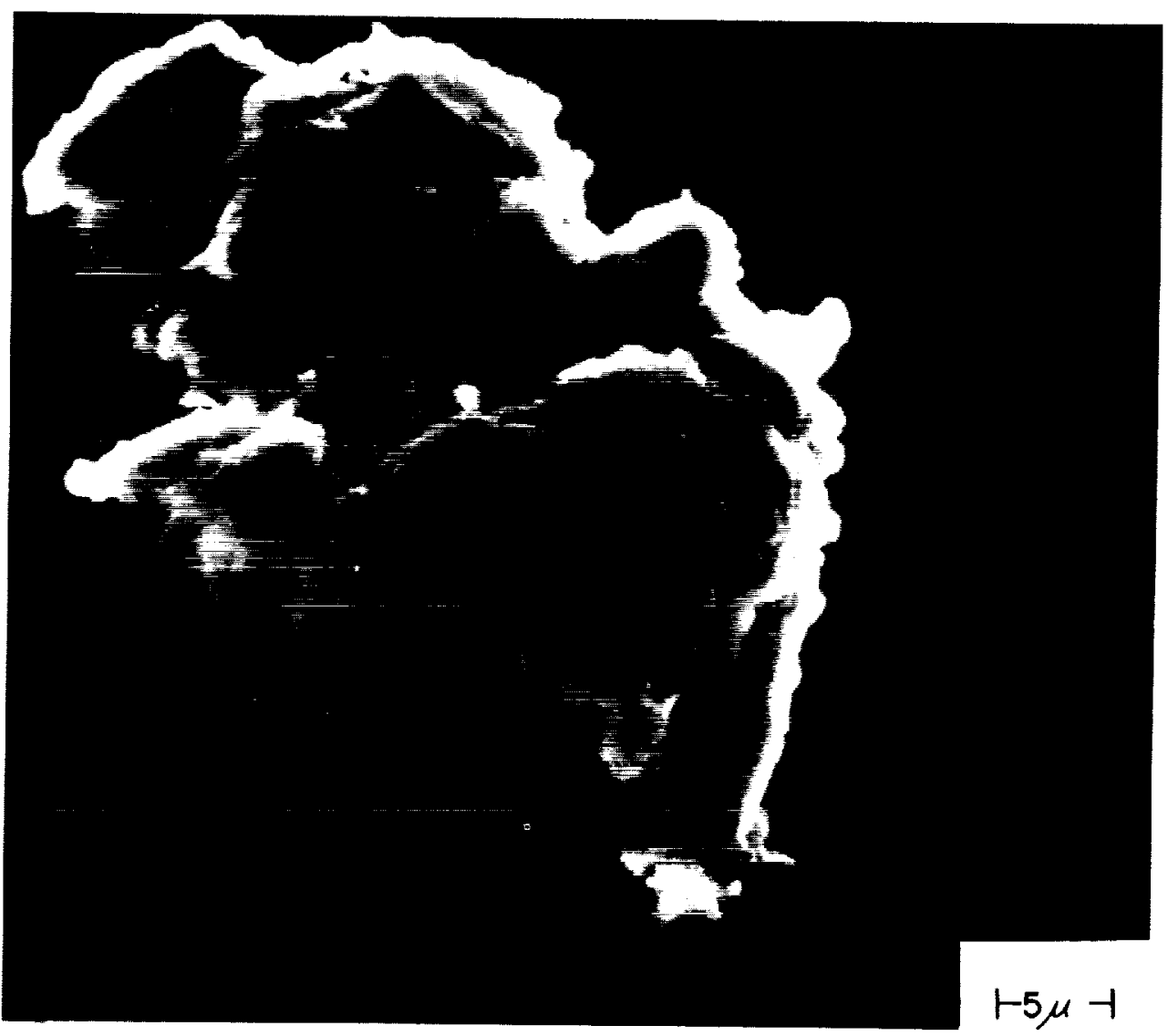

Figure 3.-Particle showing parallel flow marks. 
Only about 5 percent of our Sesame balloon particles show evidence of surface ablation and less than 0.5 perecnt of the collected particles are spheres. The absence of ablation signatures on most of our balloon particles is evidenee that the balloon particles are for the most part fragile fragments which have crumbled from larger metcoric bodies and have been partially shiclded during romtry. This conclusion is supported by the observed enhaneement in the apparent balloon flux at times of metcor shower activity (Hemonway ot al., 1967).

\section{REFERENCES}

Hemenway, C. L., HallgRen, D. S., and Coon, R. F., 1967. High altitude balloon-top collections of cosmic dust, Space Research VII, 1423-1431.

Hemenway, C. L., Hallgren, D. S., Lavdate, A. T., Patasinick, H., linzbua, T. S., AND GrIfFITH, O.K., 1971. A new high altitude balloon-top cosmic dust collection technique, Space Research XI, 393-395.

Hemenway, C. L., and Soberman, R. K., 1962. Studies of micrometeorites obtained from a recoverable sounding rocket, Astron. J., 67, 256-266.

Öplk, E., 1937. Basis of the physical theory of meteor phenomena, Pub. Ast. Obs. Tartu, 29, 1-67.

Tromsen, W. J., 1953. The annual deposit of meteoritic dust, Sky Telese., 12, 117-148.

Wurples, F. L., 1950. Theory of micro-metcorites Part $I$, in an isothermal atmosphere, Proc. Nat. Acad. Sci, 36, 687-695.

Wright, F. W., And Hodge, P. W., 1964. Composition studies of extra terrestrial particles, Annals of N.Y. Acad. of Sci., 119, 287-297. 
